\title{
EI miedo. Historia de una idea política
}

\author{
Corey Robin \\ Traducción: Guillermina Cuevas Mesa
}

Fondo de Cultura Económica, México, 2009, 499 págs.

Ivan Pincheira Torres*

Recibido: 14.11.2009

Aceptado: 07.02.0210

$* * *$

El miedo, presencia constante en la historia de la humanidad. Tanto es así que sería la primera emoción experimentada por los personajes de la Biblia. Ni deseo, ni vergüenza, sino miedo. Luego de comer del árbol prohibido, Adán se esconde de Dios y confiesa: 'tenía miedo porque estaba desnudo’. Antes de tener miedo, Adán y Eva existían y actuaban en el mundo, pero sin experiencia palpable del mismo. Atemorizados, de ahora en más, aparecen rebosantes de experiencia. De este modo, aquella primera tentación de probar lo prohibido viene a significar el paso del movimiento apático, a la acción elegida. Su historia, nuestra historia, se encuentra lista para comenzar.

Los acontecimientos del 11 de septiembre del 2001 tendrían consecuencias similares; de la pasividad en que habrían incurrido tras la caída de los regímenes comunistas y el triunfo del libre mercado, los norteamericanos pasarían a la acción más enconada contra sus nuevos enemigos. Antes del 11 de septiembre, según la denuncia conservadora, los estadounidenses vivían ociosos en un baño tibio de autismo social, regodeándose en la utopía del ciber-capital, cultivando ‘paraísos privados’ que opacaron su sentido del mundo. Pero el 11 de septiembre fue una pesadilla que los haría despertar de aquel sueño frívolo, si no es que decadente, que duró una década. El miedo que provocó el atentado a las Torres Gemelas, le habría devuelto a los Estado Unidos la claridad de que el mal existe, e hizo posible nuevamente la acción. El 11 de septiembre no fue el fin de la historia; al igual que el temor salvador de Adán y Eva, significó nada más que el principio.

Convencidos de carecer de principios que sostengan la vida pública, siempre está al acecho la posibilidad de validar la experiencia del miedo, tal como lo ha sido la experiencia global tras los acontecimiento del 11/

* Universidad Bolivariana, Santiago, Chile. Email: ivanpincheira@gmail.com 
9, como la única capaz de hacernos pasar de una sociedad de hombres y mujeres aislados en un pueblo unido. El problema, dentro de los tantos que podría suscitar una pretensión de este tipo, es que al considerar el miedo como pilar de la vida en común, nos rehusamos a reconocer que éstos, nuestros temores, no son más que los síntomas manifiestos de los conflictos permanentes en sociedades la injusticia y la desigualdad. Siendo incapaces de evidenciar los conflictos reales que hacen del miedo un instrumento político, se hace imposible la búsqueda de herramientas para enfrentar dichos conflictos; todo lo cual, en último término, redunda en que sigamos siendo sometidos y dominados por el miedo.

Estos serán los términos con que Corey Robin, académico de Ciencia Política en el Brooklyn College y en el Graduate Center de la ciudad de Nueva York, columnista en The New York Time y The Washington Post, expone los ejes de problematización que guiarán y articularán de "El miedo. Historia de una idea política”, texto galardonado con el Best First Book in Political Theory Award de la American Political Science Association.

El libro que a continuación reseñamos, habla sobre el miedo, particularmente en relación con la política moderna. Diferente de los miedos privados, como el miedo a volar o a las arañas, producto de la propia experiencia psicológica y que poco inciden más allá de nosotros mismos, lo característico de los miedos políticos es que emanan de la sociedad o tienen consecuencia para ésta.

Fue Michel Montaigne quien declaró: ‘A lo que más le temo es al miedo'. Frase inaugural para toda una tradición de teóricos y políticos que han asumido al miedo como el gran mal de la civilización, impedimento letal de la civilización, contra el cual se debiera luchar. No obstante, en ciertos autores pareciera salvarse cierta noción del miedo, no sólo porque nos ponga en alerta frente a peligros reales, impulsándonos a tomar medidas en su contra, sino porque, tal como mencionábamos más arriba, el miedo supondría una agudización del estado de experiencia; acelerando nuestras percepciones y acciones como ninguna otra emoción.

Para que el miedo se estructure como acicate de la acción política, el objeto del miedo debe formar parte del reino de la política. Si el miedo posibilita el compromiso con valores políticos como el imperio de la ley o la democracia liberal, son amenazas políticas a dichos valores los que se habrán de enfrentar. Sin embargo, escritores y líderes insistirían en considerar a gran parte de los miedos como no políticos, como si tuvieran poca relación con los problemas y las controversias que animan las discusiones y la práctica gubernamental. Asumiendo más bien el temor como un fenómeno alojado en misteriosos intersticios remitidos la mayor parte de las veces al ámbito psicológico.

Esto es lo que estaría presente en una parte importante de los análisis del 11 de septiembre. Llegándose a indicar, por ejemplo, que no era el rechazo al poder y a una política norteamericana, en alianza con Israel, de 
intromisión en Medio Oriente. Para los comentaristas conservadores, el atentado se entendía a partir de la ansiedad provocada por el avance de una cultura laica y otros valores occidentales que amenazaban el frágil sentido de identidad musulmán. Dentro de este mismo plano, otras explicaciones apuntaban a razones puramente psicológicas. Para entender lo que movió a Mohamed Atta, cabecilla de los ataques del 11 de septiembre, los analistas recomendaban analizar la materia prima de su personalidad. La cual estaba marcada por una compleja relación con las mujeres, de quienes se mantuvo alejado hasta el momento de su muerte. El cuadro estaba completo, Atta y los que conspiraron con él tenían problemas con su masculinidad; el 11 de septiembre fue un acto de jóvenes de sexualidad ambigua tratando de probar que eran hombres.

En este enfoque del miedo parece haber una contradicción. Por una parte se considera el miedo como una oportunidad tanto de unidad social frente al peligro, como de renovación políticas debido a la necesidad de tomar las medidas adecuadas. Por otra parte, sin embargo, se piensa que en los objetos, las acciones que producen temor no tendrían un sentido político. Ahí está, por ejemplo, las supuestas causales psicológicas, problemas de masculinidad, de los perpetradores del atentado a las Torres Gemelas. El problema es que al no dar una explicación política a estos actos productores de temor, y a los sujetos que los protagonizan, se les entiende y trata como enemigos incorregibles, frente a los cuales solo resta encerrarlos o matarlos. En cambio, si se entendiera los objetos de nuestros miedos como verdaderamente políticos, se discutiría sobre ellos como se hace sobre otros asuntos entendidos como problemas políticos; algunos los rechazarían, otros simpatizarían con las quejas del otro; algunos quizá no los verían tan implacables o peligrosos. La cuestión es que la tan anhelada unidad social y la tan pretendida renovación política, siempre comandada desde los sectores de elites, se efectúa desde una noción que asume el carácter no político dado a los actos productores de miedo.

No siempre se ha tenido esta percepción del miedo. Antes de la era moderna la mayoría de los escritores consideraba el miedo como un remanente de nuestras creencias morales, producto de la educación, las leyes y las instituciones políticas. A la vez que no se les entendía como instrumentos de renovación cívica, tampoco las fuentes productoras de miedos podían ser asumidas al margen de la política, todo esto debido a que el miedo dependía de consideraciones morales respecto del bien y el mal. En Aristóteles, Platón y San Agustín, por ejemplo, lo que convertía algún objeto en algo temible era la consideración de que ese acto era moralmente malo, y detrás de la adquisición de esos juicios morales siempre se encontraba la ciudad, la república, la política.

Pero hoy se tendería a no pensar en el miedo en relación a creencias y juicios morales, tampoco como una cuestión de elección; definiéndola como una emoción instintiva, subpolítica. De ahora en más al terror se le define como una reacción fisiológica ante un peligro; reacción automática, involuntaria y demasiado inescrutable como para controlarla. Entendidas 
como experiencias individuales, el miedo, el terror, no son analizados como instrumentos tradicionales de la política.

Para Corey Robin, al separarlo de la moral y de la política, el miedo pasa a transformarse en la base de estas dos últimas. Premisa que se establece como lugar común dentro de amplios sectores de la teoría política moderna. Alexis de Tocqueville, en sus escritos sobre la revolución francesa, en el reconocimiento de la desesperación por la pérdida del Antiguo Régimen y la inquietud por la democracia que se instituía, esperaba que sus contemporáneos renovaran la confianza al sentir temor; el cual debía ser puesto a trabajar a favor de la libertad. De la misma manera, para Hannah Arendt, con posterioridad del Auschwitz nazi y el Gulag soviético, los axiomas del progreso universal eran inoperantes. Siendo a propósito de esos horrores que el miedo pasaría a constituirse en el instrumento de un nuevo consenso moral y político. Más recientemente, será la académica Judith Shklar quien señalará que lo que caracteriza a la cultura liberal es el reconocimiento de la crueldad como el summum malum, el primero de todos los vicios a partir del cual se estructuran las modernas sociedades. En el 'liberalismo de miedo', como lo denominará, el temor casi instintivo a la crueldad estructurará nuestra vida en comunidad.

A contracorriente de esta tradición, nuestro autor va a argumentar que el miedo político no es un agente salvador de la sociedad, tampoco está más allá del campo de la política; por el contrario, es más bien una herramienta política, un instrumento utilizado, ya sea, por las elites gobernantes o, como asimismo, por activistas de alguna organización, todos los cuales persiguen fines políticos específicos. Al recomendar que aceptemos nuestros miedos, al ocultar los conflictos políticos que los producen, al considerar al liberalismo tan sólo como una solución y no como un problema, quienes proponen estas nociones están apoyando a las fuerzas de la sociedad que se benefician con la utilización del miedo, negando apoyo a las fuerzas sociales que tienen mucho que perder con el miedo.

Lo anterior refiere a un tipo a un tipo de miedo político; la definición e interpretación que hacen los líderes políticos de determinados objetos de temor y preocupación. Normalmente, en esta modalidad se asume que los líderes y la población influenciada tienen una identidad común, a partir de lo cual todos se sienten amenazados. Este tipo de miedo es propio de los tiempos de guerra, escenario en el que es la comunidad entre la que se ve amenazada por un enemigo externo.

Junto a éste, existe un segundo tipo de miedo político; un modo de temor que es producto de las jerarquías sociales, políticas y económicas que dividen a esa misma población. A pesar de que este miedo también es producido, ejercido o manipulado por líderes políticos, su objetivo o función específica es la intimidación interna, aplicar sanciones o amenazas para asegurarse de que un grupo conserve o aumente su poder a expensas de otro. Si, por un lado, el primer tipo de miedo implica el temor de una colectividad a riesgos ajenos a la comunidad, por ejemplo, el terrorismo 
extranjero, el segundo tipo es más íntimo y menos ficticio, siendo producido por conflictos intrínsicos a una sociedad, como, por ejemplo, la desigualdad, ya sea en cuanto a riqueza, estatus o poder. Es a partir de acá que, ubicándolo a la base del orden social, en tanto que perpetua la desigualdad, el miedo surge como un básico de control.

Concentrado en esta modalidad interna del miedo, se sostendrá que los poderosos no sólo están en condiciones de ejercer el miedo, sino que también pueden padecerlo. Los poderosos sufren el miedo de que los que ocupan rangos inferiores en la escala social se subleven un día, despojándolos de su privilegiada posición. Sin embargo, el miedo político más relevante, por cuanto llega a estructurar en forma importante la vida social, es el miedo que se siente frente al poderoso. En última instancia, éste será el centro de preocupaciones a desarrollar en el texto; más allá del actual miedo al terrorismo, o al comunismo, como lo fue durante la Guerra Fría, los miedos más importantes son los que el ciudadano común siente por sus superiores. Este tipo de miedo es represivo, garantizando que se acaten las órdenes de los superiores, o simplemente impidiendo que se haga algo por socavar la manera en que el poder está distribuido actualmente.

En su sutil cotidianidad, el lugar del trabajo es donde mejor se podría graficar esta modalidad interna del miedo en nuestras sociedades contemporáneas. Pues es en las prácticas poco reglamentadas de contratación, despido, ascenso y pérdida de categoría, en la coercitiva intimidad impuesta entre el empleador y el trabajador, supervisor y supervisado, en todas estás prácticas el miedo aparece en toda su capacidad de estructuración de lo social.

Llegados al final, no podemos dejar de señalar que cuando Corey Robin se aboca a la realización de una historia política del miedo, lo que nos propone es adentrarnos en aquella trama, desde luego compleja, en donde el miedo aparece como una de las dimensiones constitutivas, no sólo, de los Estados Unidos, sino que, más relevante aún, el miedo forma parte de la historia de Occidente, en general, y de Latinoamérica, en particular. Siendo este el sustrato a partir del cual se explica una parte importante de las reacciones, a nivel global, frente a los acontecimientos del 11 de septiembre del 2001. Es así como el miedo al terrorismo, orquestado y manipulado por los poderosos, está siendo utilizado para reorganizar la estructura de poder mundial; haciendo casi imposible sustraerse a una comunidad de amenazados. 